\title{
Vocabulary Learning Strategies (VLSs) Employed by Learners of English as a Foreign Language (EFL)
}

\author{
Prashneel Ravisan Goundar ${ }^{1}$ \\ ${ }^{1}$ School of Communication, Language \& Literature, Lautoka, Fiji \\ Correspondence: Prashneel Ravisan Goundar, School of Communication, Language \& Literature, Fiji National \\ University, Lautoka, Fiji.
}

Received: March 16, 2019 Accepted: April 18, 2019 Online Published: April 20, 2019

doi: 10.5539/elt.v12n5p177 URL: https://doi.org/10.5539/elt.v12n5p177

\begin{abstract}
Learning a new language entails various challenges, one of these is grasping the vocabulary of the language. A significant way to tackle the problem is to motivate students to become independent learners during the progression of second language (L2) vocabulary learning. Thus, this study intended to explore the use of different vocabulary learning strategies among adult English as foreign language learners and investigated the various vocabulary learning strategies and found the benefits and drawbacks associated with each strategy. It was able to select the most frequently and least frequently used VLSs by learners who have completed the language program and those who are continuing the course. Further, it found effective strategies that could be used in teaching vocabulary to students. The research used a quantitative method approach with 53 participants who were EFL learners took part in the questionnaire survey. The results of the present study reveal the common strategies that foreign language learners use in vocabulary learning. The VLSs from this study will not only benefit students of the English language but can easily to be used by learners of other second languages globally. Finally, the paper discusses different strategies at length, gives valuable recommendations in the discussion section and concludes with implications for future research.
\end{abstract}

Keywords: vocabulary learning strategies, language learning strategies, second language acquisition, vocabulary learning beliefs, English as a foreign language (EFL)

\section{Introduction}

\subsection{Engaging in Research on Vocabulary Learning Strategies}

The field of English as a foreign language (EFL) is enormous that comprises of various areas for example lexical components, phonetics, morphology, writing, speaking, and listening. Also, all the fields have been extensively researched to focus on different strategies which can suit the learners. Folse (2004) explains that 'learning a language involves learning numerous aspects about that language, these include its pronunciation, pragmatics, writing system, syntax, rhetorical modes for reading and composition, culture, and spelling, however the topmost aspect is vocabulary'. On the contrary, even though there has been a lot of research in the past, as early as the 1970 's on vocabulary learning strategies (VLSs), it has been challenging to conclude which strategy is the best to employ. As Wilkins (1972) lucidly puts it 'without grammar, very little can be conveyed, without vocabulary, nothing can be conveyed', this simply illustrates the essence of having adequate vocabulary nevertheless acquiring it can be very challenging; therefore, learners need to be equipped with strategies in-order to confront this major component.

Vocabulary learning strategy is considered as a tool that learners use to acquire vocabulary. Learners may employ different learning strategies that they assume to be an effective way of acquiring vocabulary. Ellis (1997) states 'successful learners use more strategies than unsuccessful learners. Further, the right and dynamic strategies the learners employ influence their satisfactory academic performance'. Huckin and Bloch (1993) have pointed out that 'research has shown that second-language readers rely heavily on vocabulary knowledge and that a lack of vocabulary knowledge is the largest obstacle for second language readers to overcome' (p. 154). Similarly, Haynes and Baker (1993) found the main obstacle for L2 readers 'is not a lack of reading strategies but rather insufficient vocabulary knowledge in English'.

To add on, Chamot and Kupper (1989, p. 9) define language learning strategies (LLSs) as 'techniques that 
students use to comprehend, store, and remember information and skills'. However, Oxford (2003, p. 8) provides a more recent definition LLSs as 'specific actions taken by the learners to make learning easier, faster, more enjoyable, more self-directed, more effective and more transferable to new situations' (p.8). Vocabulary learning strategies are one part of language learning strategies which in turn are part of general learning strategies (Nation, 2001). According to Nation (2001, p. 217), it is essential that a strategy must firstly 'involve choice, that is, there are several strategies to choose from'. Secondly, it must 'be complex, that is, there are several steps to learn'. Thirdly, it ought to 'require knowledge and benefit from training' and finally, it should 'increase the efficiency of vocabulary learning and vocabulary use'.

Schmitt (1997) makes a valuable point on previous studies and claims 'research has shown that many learners do use more strategies to learn vocabulary especially when compared to such integrated tasks such as listening and speaking'. But they are mostly inclined to use basic vocabulary learning strategies. Thus, Ghazal (2007) concludes that 'strategy instruction an essential part of any foreign or second language program'.

Recent years has seen a growth in the recognition of the role played by vocabulary in language learning. According to Noor and Amir (2009) attest that 'this area of learning was previously neglected due to certain dominant teaching approaches in the 1940s until the 1960s'. The 'theories underlying these approaches such as structural linguistics (Fries, 1945) and generative transformational linguistics (Chomsky, 1957) focused on teaching grammatical and phonological structures as well as emphasized on grammatical rules respectively'. In addition, 'learners were assumed that once they have learned the structural frames and the grammatical rules, they will then be able to fill in the lexical items as needed' (Noor \& Amir, 2009).

Riankamol (2008) explains that 'vocabulary are the building blocks of a language since they label objects, actions, ideas without which people cannot convey the intended meaning'. An example of this point is, when someone is thirsty in a foreign country and needs to drink water, one just has to ask someone or gesture to someone the way to drink water and just say 'water'. The receiver would immediately understand and interpret that one is thirsty. Thus, there is not an essential need for a complete sentence to be said but just one word which in this example is 'water'.

Literature indicates (Naiman et al., 1986) that 'there is no absolute advantage in using a strategy, that not all strategies have the same effect on all learners, and that choice of strategies is related to factors like attitude'. Thus, arises a need for research which seeks answers to questions of such nature that relate to what strategies can prove to be helpful to learn vocabulary of English as a foreign language.

\subsection{Background and Context of the Study}

Teaching English as a foreign/second language (TEFL/TESL) has been a field which has existed for decades. However, this field has been new to Fiji and it was not known until a language institute in Nadi began operations in 2006, which teaches students from Asian countries as well as another UK based organization, Projects Abroad Fiji which teaches students from Europe. The opening of these two English language institutes has seen more English teachers becoming interested in this field. The TEFL field has various components which need to be understood by both learners and teachers of EFL in order to provide comprehensive and meaningful learning. Nielsen (2002) states, 'second language vocabulary acquisition is a field of investigation that has seen an explosion of experimental research in the past 25 years'. This statement made by Nielsen is vital to gather how much interest has been shown to this field of study.

Further, Li (2010) highlights that vocabulary learning beliefs (VLBs), another learner variable that influences vocabulary learning (Moir \& Nation, 2002; Gu, 2005), is an under-researched area. This in turn, generates a greater need for further research in this field to address this phenomenon. The research aims at providing new strategies of learning vocabulary which can be used by learners and it will be a great asset to teachers in designing appropriate materials for EFL/ESL classrooms in Fiji. Furthermore, since it is a study of VLSs for English as a foreign language, the findings of this research can be easily adopted in international classrooms or by foreign learners and it is not limited to Fiji.

\subsection{Aim of the Study}

The principal aims and objectives of this paper are to:

1) Explore the use of different vocabulary learning strategies among adult English as foreign language learners

2) Select the most frequently and least frequently used VLSs by learners who have completed the language program and those who are continuing the course 
3) Find effective strategies that could be used in teaching vocabulary to students

\subsection{Vocabulary Learning Strategies}

Language learning strategies are methods that students employ to 'enhance their own learning'. Strategies are pivotal for language learning as they are a device for active, self-responsible learning. Learners who use appropriate language learning strategies yielded greater proficiency and self-confidence (Oxford, 1990). Most of the literature which has been studied provides a similar point of view and highlights the importance of having VLSs. Gaining knowledge about the different types of choices in VLSs will help teachers, researchers and curriculum developers to design appropriate materials for classroom purposes.

\subsubsection{Brief Outline of Major Studies on Vocabulary Learning Strategies}

Some major researches have been carried out since 1995 which include: 'Sanaoui (1995), Stoffer (1995), Moir (1996), Gu and Johnson (1996), Lawson and Hogben (1996), Schmitt (1997), Porte (1988), Kudo (1999), Kojic-Sabo and Lightbown (1999), Lin (2001), Catalan (2003), Fan (2003)'. The researches have provided insights into the process of vocabulary learning and the strategies which have been used by individuals.

Sanaoui (1995) outlined 'two distinctive approaches to vocabulary learning of adult learners: those who structured their vocabulary learning and those who did not. Structured learners engaged in independent study, did self-initiated learning activities and recorded the lexical items they were learning, reviewed such records, and practiced using vocabulary items outside the classroom'. Furthermore, Gu and Johnson (1996) discussed 'six types of strategy - guessing, dictionary, note-taking, rehearsal, encoding, and activation - together with two other factors: beliefs about vocabulary learning and metacognitive regulation. Metacognitive regulation consists of strategies for selective attention and self-initiation. The latter make the meaning of vocabulary items clear through the use of a variety of means. Guessing strategies, skillful use of dictionaries and note-taking strategies are labeled as cognitive strategies. Rehearsal and encoding categories are classified under memory strategies'. Also, 'word lists and repetition are instances of rehearsal strategies. Encoding strategies include strategies such as association, imagery, visual, auditory, semantic, and contextual encoding as well as word-structure. Activation strategies include those strategies through which learners actually use new words in different contexts' (Gu \& Johnson, 1996).

In response to the lack of a comprehensive list of vocabulary, Schmitt (1997) devised his taxonomy, self-reportedly by organizing 58 strategies 'under five types: determination, social, memory, cognitive and metacognitive'. These categories were inspired by Oxford (1990); however, some modifications were made to it. The modification included a 'distinction between discovery and consolidation strategies'. According to Schmitt (1997) 'determination strategies are used when learners are faced with discovering a new word's meaning without recourse to another person's experience'. For instance, 'learners try to discover the meaning of a new word by guessing it with the help of context, structural knowledge of language, and reference materials. It is also possible to discover the meaning of a word through asking someone for help' (Bastanfar \& Hashemi, 2010).

\subsubsection{Categorization of the Strategies}

In all research conducted on vocabulary learning strategies, four important categories are highlighted which are metacognitive strategies, cognitive, memory and activation strategies. It is very important to understand these concepts as it forms the basis of the any study being conducted in this field. Gu and Johnson (1996) lists L2 'vocabulary learning strategies as metacognitive, cognitive, memory and activation strategies'. The 'metacognitive strategies' comprises of 'selective attention and self-initiation strategies'. L1 and L2 learners who 'employ selective attention strategies know which words are important for them to learn and are essential for adequate comprehension of a passage'.

$\mathrm{Gu}$ and Johnson (1996) point out 'cognitive strategies in taxonomy as guessing strategies, skillful use of dictionaries and note-taking strategies'. They further give details on this; 'that learners using guessing strategies draw upon their background knowledge and use linguistic clues like grammatical structures of a sentence to guess the meaning of a word. Memory strategies are classified into two distinct categories; rehearsal and encoding categories. Word lists and repetition are instances of rehearsal strategies. Encoding strategies encompass such strategies as association, imagery, visual, auditory, semantic, and contextual encoding as well as word structure which includes; analyzing a word in terms of prefixes, stems, and suffixes' (Gu \& Johnson, 1996).

Finally, 'the activation strategies include those strategies through which the learners actually use new words in different contexts. For instance, learners may set sentences using the words they have just learned' (Ghazal, 2007). 


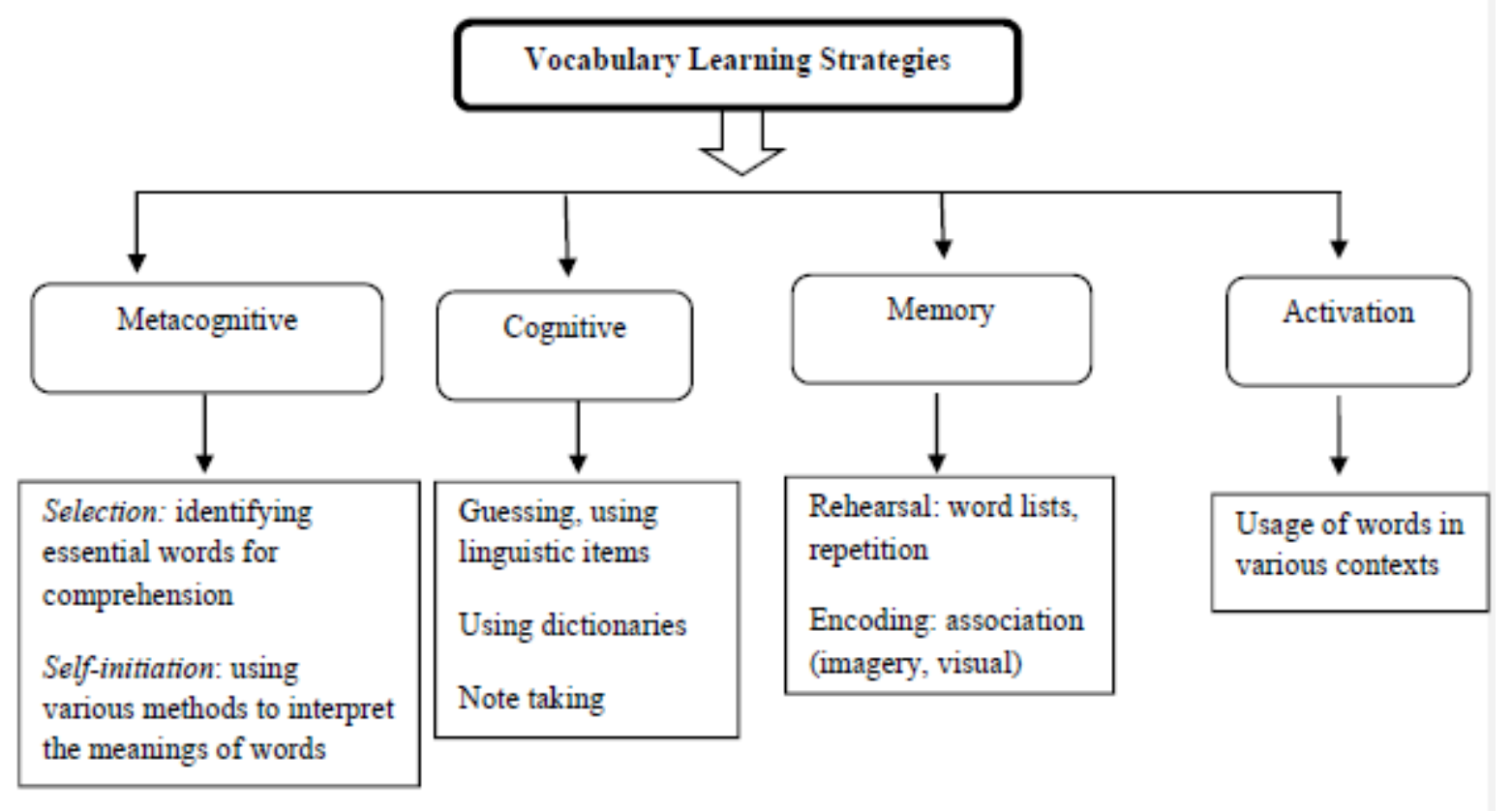

Figure 1. Illustration of the categorization of the strategies

Apart from discovering new words, Ghazal (2007) states 'learners need to employ a variety of strategies to practice and retain vocabulary. In order to accommodate this, learners thus, use a variety of social, memory, cognitive and metacognitive strategies to consolidate their vocabulary knowledge'.

\subsubsection{Concept of Good and Poor Learners}

Each learner employs different strategies to assist in learning new vocabulary. According to Peter (2003) 'a learning strategy is a series of actions a learner takes to facilitate the completion of a learning task. The most widely reported learner factors include age, sex, language aptitude, intelligence, prior knowledge, motivation, self-concept/image, personality, and cognitive and learning style'. This brings forth the concept of good learners and poor learners; those learners who are highly motivated feel a genuine need to practice the vocabulary and use this strategy to maintain the vocabulary. Scafaru and Tofan (2006) clarify that 'good learners not only use more strategies, but they also rely more heavily on different strategies than the ones poor learners use'. In a study carried out by Ahmed (1989) it was found that 'good learners were more aware of what they could learn about words, they paid more attention to collation and spelling and at the same time they were more conscious of contextual learning'. Learners are able to comprehend more new vocabulary once they use a number of strategies and do not simply stick to one which is the case for poor learners who concentrate on one method simply. On the contrary, the article by Scafaru and Tofan (2006) is very contradictory of this statement as it further mentions that statements like 'the good learners practice are not really helpful. What we need are more specific findings which tell us what the learner actually does when he practices'. In fact, it is through practice that learners commit words to memory and thus use it as confirmed by Peter (2003).

\section{Method}

A number of studies were resorted to before choosing the appropriate method for this research. Li (2010) explains 'the methodological design should be based on the purpose of the study, the research questions, and the resources and time available'. In addition, Greene (2001, p. 252) aptly puts it 'social phenomena are so complex and social problems are so intractable, all of our methodological tools are needed for understanding and for action'. Therefore, 'due to the complexity' of Second Language learning a quantitative method design was adopted to make this study more authentic. Quantitative research 'is based on positivist epistemology assuming an objective social reality that is relatively constant across time and setting' (Gall et al., 2005, p. 15). It can be therefore implied that 'quantitative research is strong in description of the SLA behaviors of a population as quantification represents a reality for that group' (Seliger \& Shohamy, 1989, p. 115). Research has shown that, studies on Vocabulary Learning Beliefs (VLB) and Vocabulary Learning Strategies (VLS) have been 'dominated 
by questionnaires (a quantitative method), and have generated somewhat diversified profiles of VLB and VLS as well as mixed results on the correlations between VLB/ VLS and learning outcomes'. Thus, the data collection method in the present study was achieved by the employment of quantitative methods (the questionnaire survey).

\subsection{Research Instruments/tools Justification}

The data collection instruments' in this study is comprised of a vocabulary learning questionnaire. The questionnaires are adequate for quantifying data (Victoria, 1999b). Therefore, the questionnaire is suitable for data collection as the present research focuses on the Vocabulary Learning Strategies of 53 EFL pupils. The questionnaire has been written in English which comprises of one major component; it consists of 48 statements grouped under 9 different categories, these are "beliefs about vocabulary learning, metacognitive regulation, guessing strategies, dictionary strategies, note-taking, memory strategies, activation, sources, and anxiety and motivation".

Participants responded using a 3-point Likert scale to indicate the frequency of the usage of each strategy, ranging from Agree (1) to disagree (3).

\subsection{Participants}

The sample of this study has been divided into various areas but following a simple random sampling method in order to have equal participation from the subjects. The first 25 questionnaires were given to students doing the EFL course at Projects Abroad (Nadi) Fiji; where classes range from beginner level to business class. The questionnaires were given to the head of school, of the institute who distributed it according to every fifth person on the attendance list in each class. Finally, 28 questionnaires were distributed to those students who have completed the English course at the institute. Furthermore, the 28 learners received this questionnaire without any preferences to level of English ability to keep into account all levels regardless of their individual intellectual ability.

\subsection{Recording and Data Analysis}

The data of this study has been analyzed using descriptive statistics where frequency counts would be tabulated and converted to percentages.

Quantitative: The method of carrying out the study, was adopted from quantitative approach, is the questionnaire. Therefore, this study will use 'an adapted version of the vocabulary strategy questionnaire proposed by Gu and Johnson (1996)' and similar to the study conducted by Noor and Amir (2009).

The data is recorded accordingly in descriptive statistics format which forms the basis of the paper and is highlighted in the conclusion of the research. The questionnaire was distributed to 53 students randomly selected between August $1^{\text {th }}$ and August $16^{\text {th }}, 2013$ and collected until August $23^{\text {rd }}$. The students were from Projects Abroad (Nadi) Fiji, and those who had completed the English language studies from the institution.

\section{Results}

The research used an adapted version of the Vocabulary Strategy questionnaire that was proposed by Gu and Johnson (1996) and similar to the study conducted by Noor and Amir (2009). The data is recorded accordingly in descriptive statistics format where 'frequency counts were tabulated and converted to percentages'.

\subsection{Beliefs about Vocabulary Learning}

Table 1. Words should be memorized

\begin{tabular}{llll}
\hline Statement & Agree & Unsure & Disagree \\
\hline The best way to remember words is to memorize word lists & $11(21 \%)$ & $23(43 \%)$ & $19(36 \%)$ \\
Repetition is the best way to remember words & $47(89 \%)$ & $5(9 \%)$ & $1(2 \%)$ \\
It is only necessary to remember one dictionary definition & $3(6 \%)$ & $14(26 \%)$ & $36(68 \%)$ \\
I can acquire a large vocabulary by memory of individual words & $9(17 \%)$ & $24(45 \%)$ & $20(38 \%)$ \\
\hline
\end{tabular}

The data revealed that $89 \%$ of learners believed that repetition was the best way to remember words. On the other hand, only $21 \%$ of learners agreed that memorization of words list was the best way to remember words. Furthermore, it was highlighted that $68 \%$ of the respondents did not agree that it was only necessary to remember one dictionary definition. 
Table 2. Words should be acquired in context (bottom-up)

\begin{tabular}{llll}
\hline Statement & Agree & Unsure & Disagree \\
\hline I can identify the meaning of most words through reading & $23(43 \%)$ & $20(38 \%)$ & $10(19 \%)$ \\
I can expand my vocabulary through reading a lot & $48(91 \%)$ & $5(9 \%)$ & $0(0 \%)$ \\
Guessing words in context is one of the best ways to learn vocabulary & $38(72 \%)$ & $11(20 \%)$ & $4(8 \%)$ \\
\hline
\end{tabular}

The research revealed that $91 \%$ of the learners stated that through reading they were able to expand their vocabulary. Moreover, $72 \%$ of the participants highlighted that "guessing words in context" was one of the best strategies to use in learning vocabulary. Also, $43 \%$ showed that they could identify most words through reading.

Table 3. Words should be studied and put to use (top down)

\begin{tabular}{llll}
\hline Statement & Agree & Unsure & Disagree \\
\hline I revise the new words I have learned & $36(68 \%)$ & $13(24 \%)$ & $4(8 \%)$ \\
$\begin{array}{l}\text { I use the words that I have learned } \\
\text { When I learned the word I pay close attention to its new usage and new }\end{array}$ & $47(89 \%)$ & $6(11 \%)$ & $0(0 \%)$ \\
meaning & & $14(26 \%)$ & $4(8 \%)$ \\
$\begin{array}{l}\text { When I have learned the word, I will recall the meaning to help me } \\
\text { understand the context }\end{array}$ & $43(81 \%)$ & $7(13 \%)$ & $3(6 \%)$ \\
\hline
\end{tabular}

In the study, $89 \%$ of the subjects stated that they used the words they learnt. In addition, $81 \%$ stated that once they had learnt the words, they recalled the meaning in order to help in understanding the context. Also, it was revealed that $66 \%$ of the respondents paid close attention to the usage and meaning of the new words.

\subsection{Metacognition Regulation}

Table 4. Self initiation strategies

\begin{tabular}{llll}
\hline Statement & Agree & Unsure & Disagree \\
\hline I think about my progress in vocabulary learning & $34(64 \%)$ & $13(25 \%)$ & $6(11 \%)$ \\
I try to find out all I can about the new words I learn & $21(40 \%)$ & $21(40 \%)$ & $11(20 \%)$ \\
I only focus on things that are related to examinations & $9(17 \%)$ & $8(15 \%)$ & $36(68 \%)$ \\
\hline
\end{tabular}

It was discovered that learners do self-reflective practices, thus it was revealed that $64 \%$ of the learners think about the progress in vocabulary learning. Furthermore, $40 \%$ of the respondents try to find out all that they can about the new word which includes; its meaning, usage, other definitions and pronunciation. The belief that learners only focus on the things that relate to examination was proved invalid as $68 \%$ of the subjects were against this concept.

Table 5. Selective attention

\begin{tabular}{|c|c|c|c|}
\hline Statement & Agree & Unsure & Disagree \\
\hline I know which words are important for me to learn & $27(51 \%)$ & $21(40 \%)$ & $5(9 \%)$ \\
\hline I look up words that I'm interested in & $44(83 \%)$ & $4(8 \%)$ & $5(9 \%)$ \\
\hline I make a note of words that seem important to me & $35(66 \%)$ & $6(11 \%)$ & $12(23 \%)$ \\
\hline I know what cues I should use in guessing the meaning of a particular word & $17(32 \%)$ & $28(53 \%)$ & $8(15 \%)$ \\
\hline
\end{tabular}


The data revealed that $83 \%$ learners took own initiative to look up words that they were interested in. Also, $51 \%$ of the respondents know the words that are important for them to learn. To assist in achieving the latter, they make notes of words which seem important and a total of $66 \%$ learners attested to this. On the contrary, $53 \%$ of the learners stated that they were unsure about what cues to use in guessing the meaning of a particular word.

\subsection{Guessing Strategies}

Table 6. Use background knowledge

\begin{tabular}{llll}
\hline Statement & Agree & Unsure & Disagree \\
\hline I skip words I don't understand & $19(36 \%)$ & $21(40 \%)$ & $13(24 \%)$ \\
I use my experience and common sense to guess & $51(96 \%)$ & $2(4 \%)$ & $0(0 \%)$ \\
I guess the meaning and then look at the dictionary (when I meet & $45(85 \%)$ & $8(15 \%)$ & $0(0 \%)$ \\
new words in reading) & & \\
\hline
\end{tabular}

It was revealed in the study that majority of the respondents used their prior knowledge (96\%) such as experience and common sense "in guessing the meaning of the words". One of the strategies that $85 \%$ of the respondents use after guessing the meaning is to look at the dictionary for its meaning and compare the answers.

Table 7. Using linguistic clues

\begin{tabular}{llll}
\hline Statement & Agree & Unsure & Disagree \\
\hline I make use of my knowledge of the topic to guess the meaning of word & $46(87 \%)$ & $6(11 \%)$ & $1(2 \%)$ \\
$\begin{array}{l}\text { Guess word's meaning from word classes, such as nouns, verbs, } \\
\text { adjectives, adverbs, to discover the meaning of new vocabulary items }\end{array}$ & $35 \%)$ & $13(25 \%)$ & $5(9 \%)$ \\
$\begin{array}{l}\text { I analyze the word structure (prefix, root and suffix) when guessing the } \\
\text { meaning of the word) }\end{array}$ & $25(47 \%)$ & $17(32 \%)$ & $11(21 \%)$ \\
\hline
\end{tabular}

In terms of linguistic cues, $66 \%$ of the learners use the word classes, such as parts of speech to guess and discover the meaning of new vocabulary items. Furthermore, $87 \%$ of the respondents highlighted that they used topical knowledge to guess the meaning of a word. It was also revealed that $47 \%$ of the learners analyze the word structure (prefix, root and suffix) in order to guess the meaning of the word.

Table 8. Dictionary strategies

\begin{tabular}{llll}
\hline Statement & Agree & Unsure & Disagree \\
\hline I use an English dictionary & $35(66 \%)$ & $10(19 \%)$ & $8(15 \%)$ \\
I use a bilingual dictionary & $41(77 \%)$ & $4(8 \%)$ & $8(15 \%)$ \\
I use the dictionary to find out the pronunciation of the word & $43(81 \%)$ & $3(6 \%)$ & $7(13 \%)$ \\
I use the dictionary to find only the meaning of the word & $17(32 \%)$ & $10(19 \%)$ & $26(49 \%)$ \\
I look in the dictionary for the grammatical patterns of the word & $32(60 \%)$ & $12(23 \%)$ & $9(17 \%)$ \\
I look in the dictionary for collocation patterns & $33(62 \%)$ & $13(25 \%)$ & $7(13 \%)$ \\
I use the dictionary to find the appropriate usage (example sentence) \\
of the word.
\end{tabular}

One of the methods to learn new vocabulary is through dictionaries. It was revealed that $66 \%$ respondents used an English dictionary. In addition, a higher data revealed that $77 \%$ learners used bilingual dictionaries. Also, it was found that a common use of the dictionary by the $81 \%$ EFL learners is to check the pronunciation of the vocabulary. On the contrary, only $32 \%$ use the dictionary to find the meaning of words. It was interesting to note that $60 \%$ of the respondents' recourse to the dictionary for the grammatical patterns of the word. Furthermore, 
$90 \%$ of the learners made use of the dictionary in locating the appropriate usage of a word which includes example sentences.

Table 9. Note taking strategies

\begin{tabular}{llll}
\hline Statement & Agree & Unsure & Disagree \\
\hline I have a vocabulary note book to list down new word & $25(47 \%)$ & $6(11 \%)$ & $22(42 \%)$ \\
$\begin{array}{l}\text { I write down the English word and translation of the word in my } \\
\text { language }\end{array}$ & $33(62 \%)$ & $10(19 \%)$ & $10(19 \%)$ \\
$\begin{array}{l}\text { I only take note the meaning of the word } \\
\begin{array}{l}\text { I take note of the usages of the word (example sentences, part of } \\
\text { speech, etc.) }\end{array}\end{array}$ & $\begin{array}{l}41(8 \%) \\
\begin{array}{l}\text { I take note of the synonym or antonym of the word } \\
\hline\end{array}\end{array}$ & $12(23 \%)$ & $37(69 \%)$ \\
& $17(32 \%)$ & $16(30 \%)$ & $20(38 \%)$ \\
\hline
\end{tabular}

A common practice in EFL classroom where learners use vocabulary was also highlighted in the research. The data showed that $47 \%$ of learners list down new words in a vocabulary note book. It was impressive to see the role played by translation as $66 \%$ of the respondents stated that they write down words and then translate the words into their own language. Furthermore, $69 \%$ of the learners disagreed that they only took note of the meaning of the word. As $58 \%$ of the learners stated they took note of the usage of the word and example sentences as well. Interesting to note through the data, $32 \%$ take note of the synonym or antonym of the words whereas; $38 \%$ do not.

Table 10. Activation strategies

\begin{tabular}{llll}
\hline Statement & Agree & Unsure & Disagree \\
\hline I make use of the words I learned in speaking and writing & $46(86 \%)$ & $4(8 \%)$ & $3(6 \%)$ \\
I make use of the words I learned in everyday situations & $24(45 \%)$ & $20(38 \%)$ & $9(17 \%)$ \\
\hline
\end{tabular}

The data revealed that $86 \%$ of the learners make use of the words that they have learned in speaking and writing. In addition, $45 \%$ of the respondents stated that they make use of words learned in everyday situations. This means that learners are confident in using words in everyday situation in either spoken or written English.

Table 11. Memory/ Repetition Strategies

\begin{tabular}{|c|c|c|c|}
\hline Statement & Agree & Unsure & Disagree \\
\hline To remember a word, I repeat it aloud to myself & $41(77 \%)$ & $5(9 \%)$ & $7(14 \%)$ \\
\hline To remember a word, I write it repeatedly & $28(53 \%)$ & $9(17 \%)$ & $16(30 \%)$ \\
\hline $\begin{array}{l}\text { I create a mental image of the new word to help me remember the } \\
\text { word }\end{array}$ & $33(62 \%)$ & $12(23 \%)$ & $8(15 \%)$ \\
\hline $\begin{array}{l}\text { To remember a word, I analyze the word by breaking it into different } \\
\text { parts (prefix, root, suffix) }\end{array}$ & $15(28 \%)$ & $16(30 \%)$ & $22(42 \%)$ \\
\hline
\end{tabular}

In terms of memory strategies, it was highlighted that $77 \%$ leaners repeat words aloud to themselves in order to remember a word whereas, $53 \%$ of the respondents also choose to write words repeatedly, in order to remember a word. Furthermore, it was interesting to note that $62 \%$ of the respondents "create a mental image of a new word" in order to remember a new word. However, only $28 \%$ of the participants analyze the words by breaking it into different parts in order to remember words. 
Table 12. Sources

\begin{tabular}{|c|c|c|c|}
\hline Statement & Agree & Unsure & Disagree \\
\hline I learn new words only in my class from my teacher & $2(4 \%)$ & $6(12 \%)$ & $45(84 \%)$ \\
\hline $\begin{array}{l}\text { I learn new words from reading English materials (e.g. newspaper, } \\
\text { novels, etc.) }\end{array}$ & $45(84 \%)$ & $4(8 \%)$ & $4(8 \%)$ \\
\hline
\end{tabular}

The data revealed that only $4 \%$ of the respondents learned new words from their teacher. In addition, it was highlighted that the major source of new vocabulary for the $84 \%$ respondents from reading English materials includes newspapers, novels, magazines to name a few.

Table 13. Anxiety

\begin{tabular}{llll}
\hline Statement & Agree & Unsure & Disagree \\
\hline I feel anxious about reading in English & $28(53 \%)$ & $10(19 \%)$ & $15(28 \%)$ \\
I skip words I don't understand when I read in English & $20(38 \%)$ & $21(40 \%)$ & $12(22 \%)$ \\
I do not know how to learn vocabulary & $4(8 \%)$ & $10(19 \%)$ & $39(73 \%)$ \\
\hline
\end{tabular}

In terms of anxiety of learning English, it was found that $53 \%$ of the learners felt anxious about reading in English. It was interesting to note that only $8 \%$ of the respondents do not know how to learn vocabulary.

\section{Discussion}

The findings and analysis of this study are presented using the questionnaire which is the 'adapted version of the vocabulary strategy questionnaire proposed by $\mathrm{Gu}$ and Johnson (1996)' and similar to the study conducted by Noor and Amir (2009). The findings of the data illustrated that the strategies most frequently used by EFL learners in this research were repetition, memorization, dictionary strategies, use of translation and using background knowledge and experience in order to increase their vocabulary.

\subsection{Common Strategies}

Table 14. Most common strategies used by English as a Foreign Language (EFL) learners

\begin{tabular}{ll}
\hline Strategy & Statistics in Percentages $(\%)$ \\
\hline Repetition & $89 \%$ \\
Reading & $91 \%$ \\
Guessing (through experience and common sense) & $96 \%$ \\
Dictionary & $90 \%$ \\
Translation & $62 \%$ \\
Note taking & $58 \%$ \\
\hline
\end{tabular}

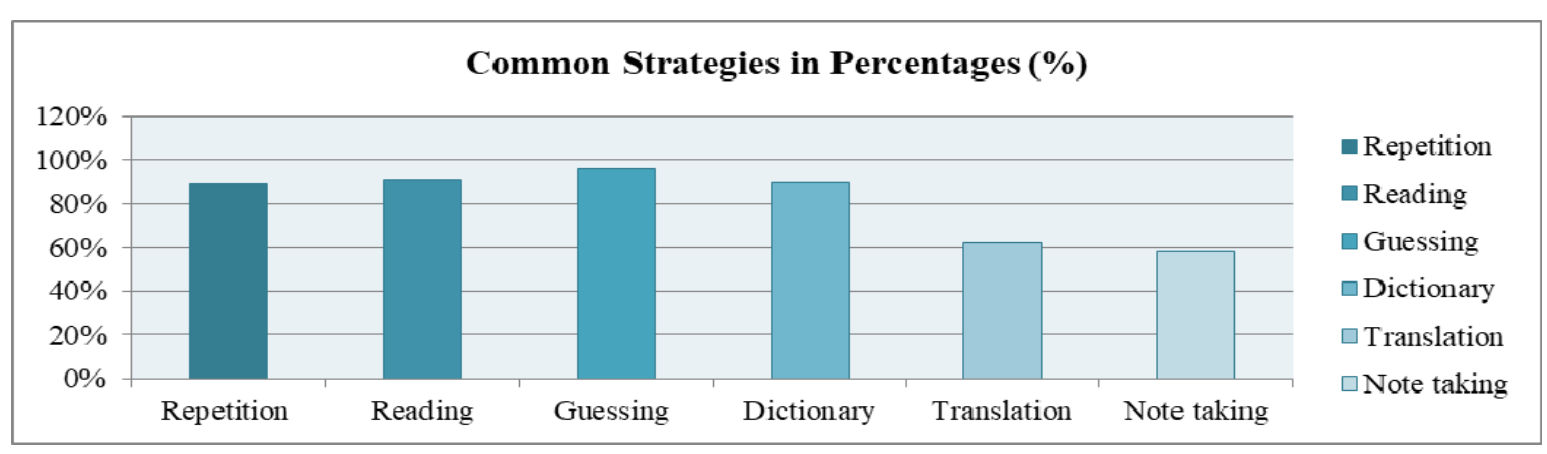

Figure 2. Common strategies in percentages $(\%)$ 
Teachers of English as a foreign/second language have always encountered that learners find it very difficult to acquire vocabulary. When learners sometimes question teachers how vocabulary can be acquired then teachers are not equipped with a variety of strategies to explain to the learners but simply two or three. The learners need proper guidance when acquiring vocabulary as it is the basis of the whole language which they want to learn. Therefore, Figure 3 will give a clear indication on the most popular strategies that learners are using. These can be applied to EFL classrooms in order assist learners in acquiring vocabulary.

4.2 Sources

Table 15. Sources of new vocabulary

\begin{tabular}{ll}
\hline Sources & Statistics in Percentages (\%) \\
\hline Teachers & $4 \%$ \\
English Materials (e.g. newspaper, novels) & $84 \%$ \\
\hline
\end{tabular}

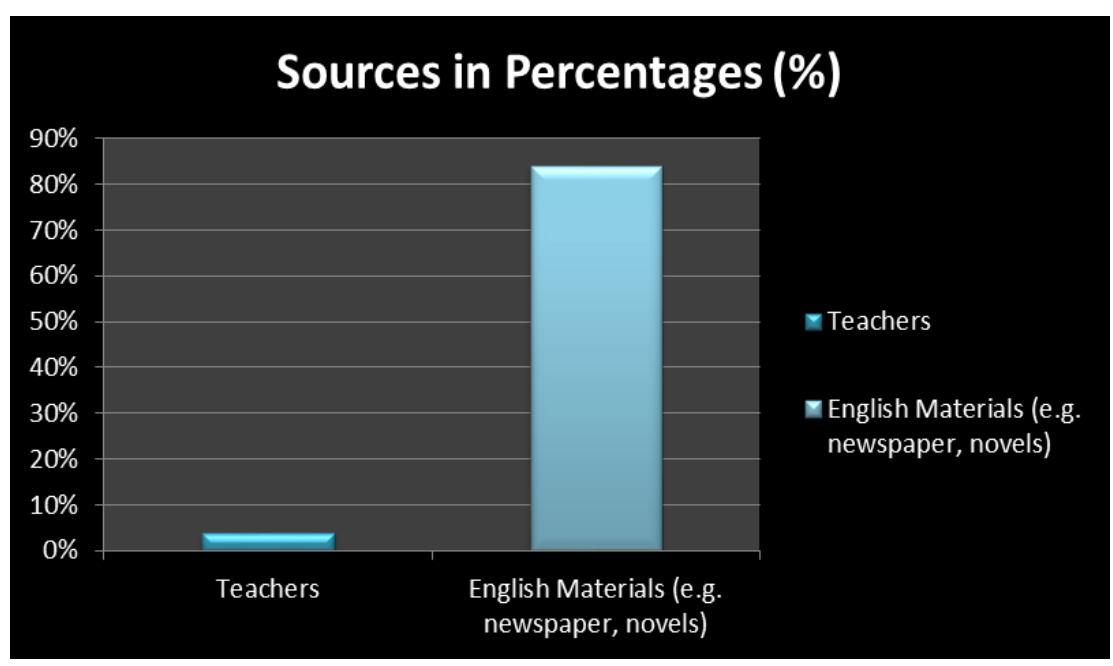

Figure 3. Graph showing the sources of new vocabulary

In the research, it was revealed that only $4 \%$ of the learners relied on the teachers to provide new vocabulary. On the contrary, $84 \%$ of the respondents' revealed that the major source of new vocabulary was through reading materials such as newspapers, novels and magazines. This implies the kind of materials which should be exposed in EFL classrooms. It also provides value insight that students rely more on reading materials then the teachers as source of new words. Therefore, EFL teachers need to review the kind of materials used in classrooms and provide a variety of reading materials so that learners can increase and enhance their vocabulary.

\subsection{Use of Dictionaries}

The various uses of dictionaries have been revealed in this study. Different learners make use of the dictionary in their own way. The statistics show the common type of dictionaries used as well as the purposes the learners use the dictionary for.

Table 16. Types and usage of dictionaries

\begin{tabular}{ll}
\hline Dictionary Types and Usage & Statistics in Percentages (\%) \\
\hline English Dictionary & $66 \%$ \\
Bilingual Dictionary & $77 \%$ \\
Pronunciation use & $81 \%$ \\
Grammatical use & $60 \%$ \\
Appropriate usage (example sentences) & $90 \%$ \\
\hline
\end{tabular}




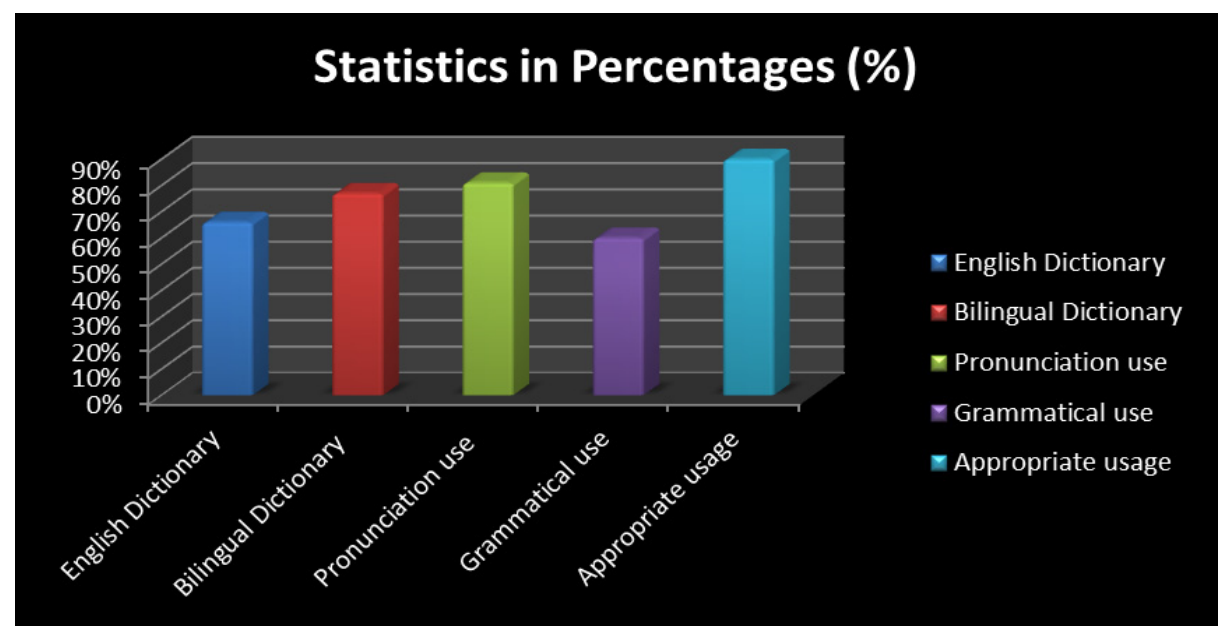

Figure 4. Dictionary type and usage

The data on dictionaries is interesting to note as shown in Figure 4. More EFL learners prefer to use bilingual dictionaries (77\%) than English dictionaries (66\%). Furthermore, learners have indicated the different uses of the dictionary. Some of the most common uses of dictionaries highlighted in the research show that $81 \%$ of learners use dictionaries to check the pronunciation of a word. In addition, $60 \%$ of the learners' use the dictionary for grammatical purposes and $90 \%$ of the learners use it to find the appropriate usage of a word which includes the example sentences. This implies the importance a dictionary has as a strategy to an EFL learner in acquiring vocabulary. Therefore, learners must be encouraged to make essential use of the dictionary in order to facilitate vocabulary learning.

To sum up, vocabulary learning is an integral process of English as a foreign Language; Ediger (1999) embraces the 'idea that developing students' vocabulary knowledge should be a major goal in each academic discipline'. In addition, it has been suggested by Anderson (1999) that 'there should be a steady study of vocabulary within a reading improvement program'. As highlighted in Table 13, the data revealed that $91 \%$ of the learners acquired their vocabulary through reading a variety of English materials. It is therefore recommended that educators introduce a variety of English reading materials in the class.

Furthermore, the dictionary is a power tool to use as highlighted earlier, the learners prefer English and bilingual dictionaries for a variety of purposes. These include checking of pronunciation, learning the grammatical usage of a word as well as checking the appropriate usage of a word such as the example sentences. In addition, Folse (2004) states 'research shows that learners who use a dictionary learn more vocabulary than those who rely on guessing from context and that learners who use a bilingual dictionary actually remember vocabulary better than those using a monolingual dictionary'. Finally, Ghazal (2007) sums up eloquently by stating that 'learning new vocabulary is a challenge to foreign language students but they can overcome by having access to a variety of vocabulary learning strategies'.

\section{Conclusion}

This study investigated the most frequently employed VLSs by adult English as foreign language learners. The various aspects of the study and the methods that were used in order to achieve the objectives will be significant to a larger audience of language learning. Guessing strategy showed as the most frequent VLS employed by EFL students. Further, the study revealed that EFL students commonly used repetition, memorization, dictionary strategies, use of translation and using background knowledge and experience in order to increase their vocabulary. Folse (2004) claims 'perhaps the recent interest in second language vocabulary research will also mean a rethinking of the way we approach the teaching of vocabulary including the necessity to teach vocabulary extensively to our students'. Further, 'for too long, second language teaching has been dominated by an emphasis on communication, but accurate communication depends largely on an extensive knowledge of vocabulary' (Folse, 2004). Despite the fact that there has been much research in finding the best strategies learners can use in order to acquire new vocabulary, the papers reviewed show that there is still great potential in this area. In fact, it is very difficult to conclude which strategy is best to be employed by learners; the research shows that if learners use a variety of strategies then only they will be able to learn more vocabulary. Gu (2003) explains that Vocabulary Learning Strategies are an indispensable tool in 'describing and explaining the 
vocabulary development of a foreign language'. Also, VLS are tools for empowering students to make better decisions in terms of what to learn and how to learn.

The focus of attention should be on how actually vocabulary acquisition takes place in order to understand the strategies that can be applied to make significant benefits to English as Foreign Language learners. One of the first question's that is asked a large number of times in EFL/ESL classes is how to learn new vocabulary of the English language, and from the research note taking and making effective use of a dictionary proves to be a good strategy. The "change in the status of vocabulary in language learning has affected teaching and learning practices' together with 'materials writing which has become more selective about what vocabulary to include' (O'Dell, 1997). Therefore, the analysis of various strategies highlighted in this research is worth employing and introducing to EFL learners. There is also potential for future research in this field and researchers can use the data from this study as future framework or as a starting point. Implication could include looking at VLSs of other languages apart from English or how these strategies affect the academic performance of the learners.

\section{References}

Ahmed, M. O. (1989). Vocabulary learning strategies. In P. Meara (Ed.), Beyond words (pp. 3-14). London: British Association for Applied Linguistics, in association with Centre for Information on Language Teaching and Research.

Anderson, N. (1999). Exploring Second Language Reading. Canada: Heinle \& Heinle Publishers.

Asgari, A., \& Mustapha, G. B. (2011). The Type of Vocabulary Learning Strategies Used by ESL Students in University Putra Malaysia. English Language Teaching, 4(2), 84.

Bastanfar, A., \& Hashemi, T. (2010). Vocabulary Learning Strategies and ELT Materials; A Study of the Extent to Which VLS Research Informs Local Coursebooks in Iran. International Education Studies, 3(3), 158. https://doi.org/10.5539/ies.v3n3p158

Bei, Z. (2011). A Study of the Vocabulary Learning Strategies Used by Chinese Students (Doctoral dissertation, Kristianstad University).

Chung, S. F. (2012). Research-Based Vocabulary Instruction for English Language Learners. Reading, 12(2).

Creswell, J. W., \& Clark, V. L. P. (2007). Designing and conducting mixed methods research. Thousand Oaks, CA: Sage Publications. https://doi.org/10.1177/1558689807306132

Cusen, G., \& Buja, E. (2009). The role of theory in applied linguistics research: A study of vocabulary learning strategies. Bulletin of the Transilvania University of Brasov, 2, 51. description, acquisition and pedagogy. Cambridge: Cambridge University Press.

Ediger, M (1999). Reading and Vocabulary Development. Journal of Instructional Psychology.

Ellis, N. C. (1997). Vocabulary acquisition: Word structure, collocation, grammar, and meaning. Cambridge University Press.

Folse, K. S. (2004). Myths about teaching and learning second language vocabulary: What recent research says. TESL Reporter, 37(2), 1-13.

Ghazal, L. (2007). Learning vocabulary in EFL contexts through vocabulary learning strategies. Novitas-Royal, $1(2), 84-91$.

Gu, P. Y. (2003). Vocabulary learning in a second language: Person, task, context and strategies. TESL-EJ, 7(2), $1-25$.

Gu, Y. (2010). Learning strategies for vocabulary development. Reflections on English Language Teaching, 9(2), $105-18$

Gu, Y., \& Johnson, R. K. (1996). Vocabulary learning strategies and language learning outcomes. Language Learning, 46(4), 643-679. https://doi.org/10.1111/j.1467-1770.1996.tb01355.x

Harmon, J. M., \& Wood, K. D. (2008). Research Summary: Vocabulary teaching and learning across disciplines. Retrieved from http://www.nmsa.org/Research/ResearchSummaries/VocabularyTeaching/tabid/1728/ Default.aspx

Kafipour, R., Yazdi, M., Soori, A., \& Shokrpour, N. (2011). Vocabulary Levels and Vocabulary learning strategies of Iranian Undergraduate students. Studies in Literature and Language, 3(3), 64-71.

Lai, Y. L. (2005). Teaching vocabulary learning strategies: awareness, beliefs, and practices. A survey of Taiwanese EFL senior high school teachers. Unpublished MA Thesis, The University of Essex, Essex, 
England.

Lawson, M. J., \& Hogben, D. (1996). The Vocabulary-Learning Strategies of Foreign-Language Students. Language Learning, 46(1), 101-135. https://doi.org/10.1111/j.1467-1770.1996.tb00642.x

Li, S. (2010). Vocabulary Learning Beliefs, Strategies and Language Learning Outcomes: a study of Chinese learners of English in Higher Vocational Education (Doctoral dissertation, AUT University).

Mayuree, S. (2007). English vocabulary learning strategies employed by rajabhat university students.

Meara, P. (1980, October). Vocabulary acquisition: A neglected aspect of language learning. Language Teaching and Linguistics: Abstracts (Vol. 13, No. 4, pp. 221-246). https://doi.org/10.1017/S0261444800008879

Nation, P. (2001). Learning vocabulary in another language. Cambridge: Cambridge University Press. https://doi.org/10.1017/CBO9781139524759

Nielsen, B. (2002). A review of research into vocabulary learning and acquisition.

Noor, M. N., \& Amir, Z. (2009). Exploring the Vocabulary Learning Strategies of EFL learners. Language and Culture: Creating and Fostering Global Communities. 7th International Conference by the School of Studies and Linguistics Faculty of Social Sciences and Humanities, 313-327.

Ranalli, J. M. (2003). The treatment of key vocabulary learning strategies in current ELT coursebooks: repetition, resource use, recording (Doctoral dissertation, University of Birmingham).

Resnik, D. B. (2007). What is ethics in research and why is it important. Retrieved from http://www.niehs.nih.gov/research/resources/bioethics/whatis.cfm

Riankamol, N. (2008). A survey study of vocabulary learning strategies of gifted English students at Triam Udomsuksa School in the first semester of academic year 2008 (Doctoral dissertation, Thammasat University Bangkok, Thailand).

Sanaoui, R. (1995). Adult learners' approaches to learning vocabulary in second languages. The Modern Language Journal, 79(1), 15-28. https://doi.org/10.1111/j.1540-4781.1995.tb05410.x

Scafaru, M., \& Tofan, L. (2006). Vocabulary learning strategies.

Schmitt, N. (Ed.). (1997). Vocabulary: Description, acquisition and pedagogy. Ernst Klett Sprachen.

Scholfield, P., Cluster analysis in the study language variation, farthcoming.

Seibert, L. C. (1927). An experiment in learning French vocabulary. Journal of Educational Psychology, 18(5), 294. https://doi.org/10.1037/h0074206

Stern, H. H. (1983). Fundamental Concepts of Language Teaching: Historical and Interdisciplinary Perspectives on Applied Linguistic Research. OUP Oxford.

Widiyanti, R. A. What Are the Factors Influencing the Use of Vocabulary Learning Strategies? -A Research Proposal.

Xhaferi, B., \& Xhaferi, G. (2010). Vocabulary learning strategies used by students at SEEU in terms of gender and teachers' attitudes toward teaching vocabulary. Tetove: CIP-Katalogizacija vo publikacija Nacionalna $i$ univerzitetska biblioteka" Sv. Kliment Ohridski", Shkup.

\section{Copyrights}

Copyright for this article is retained by the author(s), with first publication rights granted to the journal.

This is an open-access article distributed under the terms and conditions of the Creative Commons Attribution license (http://creativecommons.org/licenses/by/4.0/). 